\title{
Outcomes of long term treatments of type I hereditary angioedema in a Turkish family*
}

\author{
Gulsen Akoglu ${ }^{1}$ \\ Gokhan Yildiz ${ }^{3}$
}

\author{
Belgin Kesim² \\ Ahmet Metin ${ }^{1}$
}

DOI: http://dx.doi.org/10.1590/abd1806-4841.20175899

\begin{abstract}
BACKGROUND: Hereditary angioedema is a rare autosomal dominantly inherited immunodeficiency disorder characterized by potentially life-threatening angioedema attacks.

ОвјестіVE: We aimed to investigate the clinical and genetic features of a family with angioedema attacks.

METHODS: The medical history, clinical features and C1-INH gene mutation of a Turkish family were investigated and outcomes of long-term treatments were described.

RESULTS: Five members had experienced recurrent swellings on the face and extremities triggered by trauma. They were all misdiagnosed as familial Mediterranean fever (FMF) depending on frequent abdominal pain and were on colchicine therapy for a long time. They had low C4 and C1-INH protein concentrations and functions. A mutation (c.1247T>A) in C1-INH gene was detected. They were diagnosed as having hereditary angioedema with C1-INH deficiency (C1-INH hereditary angioedema) for the first time. Three of them benefited from danazol treatment without any significant adverse events and one received weekly $\mathrm{C} 1$ esterase replacement treatment instead of danazol since she had a medical history of thromboembolic stroke.

STUDY LIMITATIONS: Small sample size of participants.

CONCLUSION: Patients with C1-INH hereditary angioedema may be misdiagnosed as having familial Mediterranean fever in regions where the disorder is endemic. Medical history, suspicion of hereditary angioedema and laboratory evaluations of patients and their family members lead the correct diagnoses of hereditary angioedema. Danazol and C1 replacement treatments provide significant reduction in hereditary angioedema attacks.
\end{abstract}

Keywords: Complement C1 inhibitor protein; Danazol; Hereditary Angioedema Types I and II

\section{INTRODUCTION}

Hereditary angioedema (HAE) is a rare autosomal dominantly inherited disorder characterized by potentially life-threatening angioedema attacks. It affects about 1:10000 to 50000 individuals of different populations. ${ }^{1}$ Hereditary angioedema is classified into two subtypes: HAE with C1 inhibitor deficiency (C1-INH-HAE) and HAE with normal C1-INH caused by an unknown origin or associated with factor XII mutations. ${ }^{2} \mathrm{C} 1-\mathrm{INH}$ is a serine protease inhibitor that regulates inflammatory, complement and kinin forming pathways. ${ }^{3} \mathrm{C} 1$-INH gene (or SERPING1) mutations cause alterations in the structure and function of $\mathrm{C} 1-\mathrm{INH}$ protein, which lead to two phenotypic variants of C1-INH-HAE. C1-INH gene mutations leading to low levels of C1-INH protein causes type 1 of the disease. Type 2 presents normal or elevated levels of plasma protein with low C1-INH function. ${ }^{2}$

C1-INH/SERPING1 gene is located on chromosome 11q12-q13.1. More than 345 mutations have been described causing C1-INH-HAE in unrelated patients (http:// portal.biobase-international.com/hgmd). Missense mutations and frame shift alterations are mainly involved in the pathogenesis. Although systematic muta- tion analysis of C1- INH gene has been performed in many different ethnic populations, correlation between genotype and phenotype of HAE could not be defined. ${ }^{2,4,5}$ However, some recent studies indicated that carrying $\mathrm{C} 1-\mathrm{INH}$ gene missense mutations may represent a less severe form of C1-INH-HAE phenotype and patients with genetic alterations in the genes encoding proteins other than $\mathrm{C} 1-\mathrm{INH}$ gene may be involved in the pathogenesis of angioedema. ${ }^{6,7}$

Patients with HAE should be treated both during angioedema attacks and for prophylaxis. On demand therapy (therapy during angioedema attacks) is made by fresh frozen plasma or C1INH concentrate to replace the deficient C1-INH esterase inhibitor. Kallikrein inhibitors (such as ecallantide) and bradykinin B2 receptor antagonists (e. g. icatibant) are additional, possible therapeutic options for the treatment of edema attacks. Long-term prophylaxis is very important for patients who experience frequent and severe episodes of angioedema. Danazol is the main agent used for such kind of prophylaxis and follow-up and monitoring of drug adverse events and toxicity is mandatory. ${ }^{2}$

\footnotetext{
Received on 08.04.2016.

Approved by the Advisory Board and accepted for publication on 13.07.2016.

* Study conducted at the Ankara Ataturk Training and Education Hospital - Ankara, Turkey.

Financial support: None.

Conflict of interest: None
}

Dermatovenereology Clinic, Ataturk Training and Research Hospital - Ankara, Turkey.

Medical Genetics, Sisli Hamidiye Etfal Training and Research Hospital - Istanbul, Turkey.

Medical Biology, Faculty of Medicine, Erzincan University- Erzincan, Turkey.

@2017 by Anais Brasileiros de Dermatologia 
Epidemiology of HAE, genotypic features of the disorder, efficacy and adverse events of treatments applied have been investigated in large case and family studies in different populations. However, knowledge on clinical and genetic features of Turkish population is limited. In the present study, we investigated the clinical and genetic features of seven related patients and described the outcomes of long-term treatment of C1-INH-HAE.

\section{METHODS}

\section{Subjects}

The proband (Patient 1) was a 58-year-old woman who was referred from emergency department for periorbital, lip and uvula edema. She had hit her head on a door before swellings. She

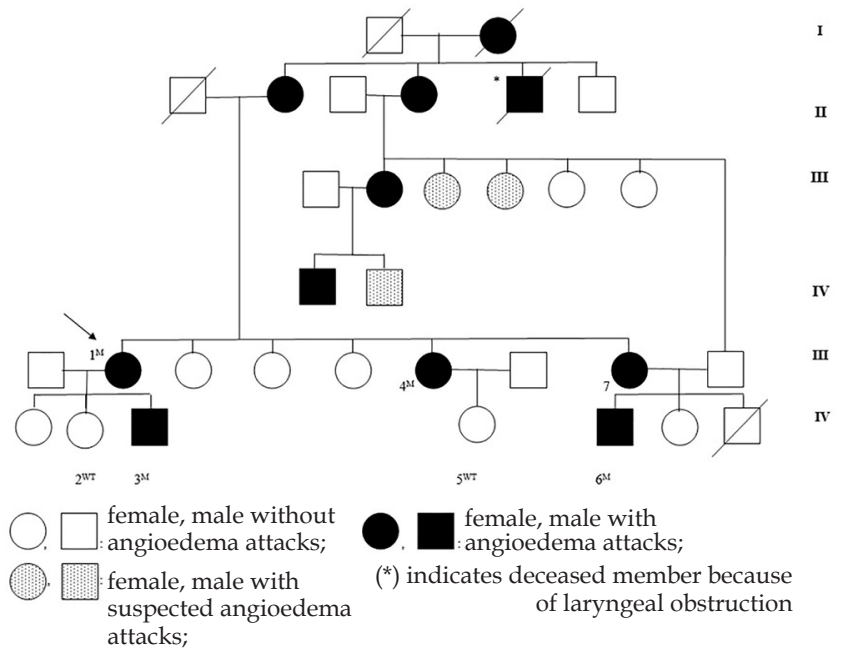

FIGURE 1: Pedigree of the family with hereditary angioedema. Symbols with a slash indicate deceased family members. The arrow indicates the index patient. Numbers indicate the cases genetically investigated in this study. Superscripts show the results of genetic analysis (M: mutant for p.Leu416X (c.1247T>A) mutation in the 7th exon of C1-INH gene; WT: wild type). has had angioedema attacks without urticarial lesions for about 30 years. Her family history revealed that her mother, son, sisters, aunt, some cousins and nephews had similar swelling attacks (pedigree is in figure 1). Her uncle had died because of laryngeal obstruction during an edema attack. Among the family members, proband's son (Patient 3), her two sisters (Patients 4 and 7) and one nephew (Patient 6) who had angioedema attacks and her daughter (Patient 2) and nephew (Patient 5), who were asymptomatic, were available for clinical and laboratory investigations for HAE.

\section{Genetic analysis}

All these patients, except for Patient 7, were accepted for genetic analysis for C1-INH gene mutation. Peripheral blood samples were collected into $5 \mathrm{ml} \mathrm{K} \mathrm{K}_{3}$ EDTA tubes and DNA was isolated by a solution-based kit (Mammalian Blood Isolation Kit-Roche, Istanbul). Deep intronic primers were designed to cover all eight exons of C1-INH gene (NM_000062.2), including the exon-intron boundaries and promoter region to secure to identify all the point mutations, small insertion and deletions described up to date (Table 1). Each region was amplified in $50 \mu 1$ reaction mixtures as directed in the instructions contained in the Taq Polymerase Enzyme Kit (Fermentas-Elips, Istanbul) under optimum Tm temperatures $\left(+/-2^{\circ} \mathrm{C}\right)$ of the primers in PTC-200 (MJ Research-Biorad, Medgen, Istanbul). PCR products were purified (GeneMark-Genova, Istanbul) and sequenced in ABI 3130 (Duzen Laboratory, Istanbul). Sequencing chromatograms were analyzed by using the public free blast programs (http://genome.ucsc.edu/ and http://www.ncbi.nlm.nih.gov/).

The identified mutations were confirmed by independent reactions and by family members' DNA whose samples were specifically sequenced for the exon that was shown to carry a mutation in the index.

\section{RESULTS} tation results

Clinical and laboratory evaluation and C1-INH gene muDemographic and clinical features of all cases are summa-

\section{TABLE 1: Primers used for C1-INH gene amplification and sequencing ${ }^{1}$}

\begin{tabular}{|c|c|c|c|}
\hline Primers & Sequences & Covered gene region & Fragment size, bp \\
\hline C1INH F 1 & 5'-CTG CGG AGC ACA TTT TGT-3' & \multirow{2}{*}{ promoter and exon 1} & 487 \\
\hline C1INH R 1 & 5'-GAA GCA AGC CTA TAG AGA-3' & & \\
\hline C1INH F 2 & 5'-GGA GGG AAT TCG CTA AGA-3' & \multirow{2}{*}{ exon 2} & 283 \\
\hline C1INH R 2 & 5'-TGA AGG GTT AAT CCT CAG-3' & & \\
\hline C1INH F 3 & 5'-CAC АТС САС АСС ТTC ТСТ Т-3' & \multirow{2}{*}{ exon 3} & 764 \\
\hline C1INH R 3 & 5'-GAA ATG ATG GAA TGT TCA AGA-3' & & \\
\hline C1INH F 4 & 5'-CAG GGA ATA CCC TCC ATT-3' & \multirow{2}{*}{ exon 3} & 357 \\
\hline C1INH R 4 & 5’-TCC ATC CCT GAT ACT GTA G-3' & & \\
\hline C1INH F 5/6 & 5'-GCA TGC TCA CTC TCA AAT-3' & \multirow{2}{*}{ exon 4} & 734 \\
\hline C1INH R 5/6 & 5'-GGA GTA GAA GTG ATG AAT T-3' & & \\
\hline C1INH F 7 & 5'-CTT AGG TCT GAC TGA TGC T-3' & \multirow{2}{*}{ exons 5 and 6} & 482 \\
\hline C1INH R 7 & 5'-TAA CTT GCA GGG TTG CAG-3' & & \\
\hline C1INH F 8 & 5'-CTA ATA GAG GAT CCC ACG A-3' & \multirow{2}{*}{ exon 8} & 890 \\
\hline C1INH R 8 & 5'-GCT GGG CAT GGT GGC AA-3' & & \\
\hline
\end{tabular}


rized in table 2. Swelling attacks emerged between one (Patient 7) and 28 (Patient 1) years of age. Trauma was the most frequent trigger for angioedema. The proband had swellings attacks every two weeks, lasting up to one week. The daughter (Patient 2) and one of the nephews (Patient 5) of Patient 1 did not have any swelling attacks until now. Abdominal attacks were common and all symptomatic five patients were misdiagnosed as having familial Mediterranean fever (FMF) in other health centers and put on colchicine treatment for a long time. Patient 7 had the most severe and frequent angioedema attacks as laryngeal obstruction and severe abdominal pain. Her medical history revealed stroke due to thrombosis. Patient 3 had experienced severe abdominal attacks initiated in pre-puberty until about his twenties. He had no angioedema attacks for about 13 years. Total blood counts with differentials, liver, kidney and thyroid function tests, anti-thyroid autoantibodies, and fibrinogen levels were within normal limits in all patients. Levels of C4, C1-INH protein and function are given in table 3. C1-INH gene mutation analyses demonstrated p.Leu416X (c.1247T >A) mutation in the $7^{\text {th }}$ exon of C1-INH gene leading to a premature stop codon in Patients 1, 3, 4 and 6 (Graph 1).

Depending on medical and family history, clinical and laboratory findings, all these symptomatic patients, for the first time, were diagnosed as having C1-INH-HAE type I.

\section{Managements}

Patient 1 was treated with fresh frozen plasma and swellings completely regressed. She was put on $200 \mathrm{mg} / \mathrm{d}$ danazol prophylaxis. After two months, the dosage was reduced to $100 \mathrm{mg} / \mathrm{d}$. The patient is now taking 50mg danazol every other day and she is still on her regular follow-ups without any other angioedema attacks for five years. Although she was symptom free, danazol therapy was not stopped due to her willing to continue the therapy because of being very anxious for having a serious attack otherwise. Patient 4 also initiated danazol at the same dosages; however, she suffered drug-induced dizziness, which required reducing the dosage to $50 \mathrm{mg} / \mathrm{d}$. She is still on $50 \mathrm{mg} / \mathrm{d}$ danazol therapy for two years, having only infrequent mild swellings on the extremities. Patient six was also put on danazol therapy with a dosage of $100 \mathrm{mg} / \mathrm{d}$ for 6 months, and then 50mg/g for two years. Weekly C1 esterase replacement therapy was initiated for angioedema prophylaxis for Patient 7 since danazol therapy was not suitable due to previous thrombotic stroke event. During the first year of follow-up period, treatment provided significant reduction of severity and frequency of life threatening attacks. Since Patient 3 was free of attacks for years, no therapy was administered and avoidance of trauma and short-term prophylaxis when needed were recommended (Table 4).

No laboratory abnormalities were detected during longterm prophylactic treatment. Annual ultrasonography examinations of liver were normal in Patient 1. Liver ultrasonography revealed two small lesions, suggesting hemangiomas in Patient 4. Dynamic contrast enhanced magnetic resonance imaging confirmed hemangiomas to be smaller than reported in ultrasonography. Gastroenterology consultation recommended imaging examinations of liver every six months during the minimal effective danazol maintenance therapy. Grade 3 hepatosteatosis was reported on ultrasonography in the last visit of Patient 6 . Switching to fibrinolytic therapy was not successful. Since normal liver structure was detected in magnetic resonance imaging, minimal danazol therapy was continued with close follow-up for liver functions.

\begin{tabular}{|c|c|c|c|c|}
\hline $\begin{array}{l}\text { Case } \\
\text { Nr. }\end{array}$ & $\begin{array}{c}\mathrm{C} 4 \\
(16-38 \mathrm{mg} / \mathrm{dl})\end{array}$ & $\begin{array}{c}\text { C1-INH } \\
\text { protein } \\
(18-32 \mathrm{mg} / \mathrm{dl})\end{array}$ & $\begin{array}{l}\text { C1-INH } \\
\text { function } \\
(70-130 \%)\end{array}$ & $\begin{array}{c}\text { C1-INH } \\
\text { gene } \\
\text { mutation }\end{array}$ \\
\hline 1 & $0.06(\downarrow)$ & $15.8(\downarrow)$ & $0.05(\downarrow)$ & + \\
\hline 2 & $15.6(\downarrow)$ & $20.9(\mathrm{~N})$ & $100(\mathrm{~N})$ & - \\
\hline 3 & $18.3(\mathrm{~N})$ & $19.9(\mathrm{~N})$ & $29(\downarrow)$ & + \\
\hline 4 & $2.86(\downarrow)$ & $3.29(\downarrow)$ & $35(\downarrow)$ & + \\
\hline 5 & $15.3(\downarrow)$ & $23.6(\mathrm{~N})$ & $108(\mathrm{~N})$ & - \\
\hline 6 & $2.41(\downarrow)$ & $12(\downarrow)$ & $0.06(\downarrow)$ & + \\
\hline 7 & $14.3(\downarrow)$ & $5.37(\downarrow)$ & $<1(\downarrow)$ & $\mathrm{N} / \mathrm{A}$ \\
\hline
\end{tabular}

\begin{tabular}{|c|c|c|c|c|c|c|}
\hline $\begin{array}{l}\text { Case } \\
\text { Nr. }\end{array}$ & Age (year)/ sex & $\begin{array}{l}\text { Age of onset } \\
\text { (year) }\end{array}$ & $\begin{array}{l}\text { Lag time for } \\
\text { diagnosis } \\
\text { (years) }^{* *}\end{array}$ & $\begin{array}{l}\text { Sites involved during } \\
\text { angioedema attacks }\end{array}$ & Triggering factors & $\begin{array}{l}\text { Misdiagnosis of } \\
\text { FMF }\end{array}$ \\
\hline 1 & $58 / F$ & 28 & 30 & facial, laryngeal, abdominal & $\begin{array}{l}\text { trauma, pressure, } \\
\text { dental surgery }\end{array}$ & + \\
\hline $2^{*}$ & $33 / F$ & - & - & - & - & - \\
\hline 3 & $33 / \mathrm{M}$ & 12 & 21 & abdominal & unknown & + \\
\hline 4 & $51 / \mathrm{F}$ & 14 & 37 & facial and abdominal & $\begin{array}{l}\text { hair epilation, dental } \\
\text { surgery }\end{array}$ & + \\
\hline $5^{*}$ & $10 / F$ & - & - & - & - & - \\
\hline 6 & $31 / \mathrm{M}$ & 5 & 26 & $\begin{array}{l}\text { facial, upper extremities } \\
\text { abdominal }\end{array}$ & trauma & + \\
\hline 7 & $53 / F$ & 1 & 52 & $\begin{array}{l}\text { facial, genital, upper extremities } \\
\text { abdominal }\end{array}$ & $\begin{array}{l}\text { trauma, dental } \\
\text { surgery }\end{array}$ & + \\
\hline
\end{tabular}

FMF: Familial Mediterranean fever; ${ }^{*}$ Cases with no complaints of angioedema attacks; ** Lag time represents the duration between the first symptom and diagnosis of C1-INH-HAE. 
TABLE 4: Treatment strategies and follow-up outcomes of patients with hereditary angioedema

\begin{tabular}{|c|c|c|c|c|}
\hline \multirow{2}{*}{$\begin{array}{l}\text { Case } \\
\text { Nr. }\end{array}$} & \multicolumn{2}{|r|}{ Treatment } & \multicolumn{2}{|c|}{ Follow-ups } \\
\hline & On demand therapy & Long term prophylaxis & Laboratory tests & Detected liver pathology \\
\hline 1 & & Danazol & & \\
\hline & Fresh frozen plasma & $\begin{array}{l}200 \mathrm{mg} / \mathrm{d} \text { for } 2 \text { months; } 100 \mathrm{mg} / \mathrm{d} \text { for } 2 \text { months; } 50 \mathrm{mg} \\
\text { every other day for } 5 \text { years: no attacks }\end{array}$ & Normal & None \\
\hline 3 & - & No therapy since no attacks for a long time & Normal & None \\
\hline 4 & - & $\begin{array}{l}\text { Danazol } \\
\text { 100mg/d: dizziness; } 50 \mathrm{mg} / \mathrm{d} \text { for } 2 \text { years: infrequent mild } \\
\text { swellings on the extremities }\end{array}$ & Normal & Hemangioma \\
\hline 6 & - & $\begin{array}{l}\text { Danazol } \\
\text { 100mg/d for } 6 \text { months; } 50 \mathrm{mg} / \mathrm{d} \text { for } 2 \text { years: no attacks } \\
\text { Trial of tranexamic acid: no benefit }\end{array}$ & Normal & $\begin{array}{l}\text { Stage } 3 \\
\text { hepatosteatosis with } \\
\text { normal liver structure }\end{array}$ \\
\hline 7 & C1-INH concentrate & Weekly C1-INH replacement therapy & Normal & $\begin{array}{l}\text { Unavailable for } \\
\text { examinations }\end{array}$ \\
\hline
\end{tabular}

\section{DISCUSSION}

This study demonstrated a nucleotide substation T>A encoding leucine amino acid in exon 7 of $\mathrm{C} 1$ - INH gene resulting in a premature stop codon causing C1-INH-HAE type I in a Turkish family. This kind of mutation was described by Pappalardo et al. ${ }^{8}$ This is a nonsense mutation in the upstream from the reactive site that may affect mRNA or protein stability. The knowledge about genetic features of Turkish patients having HAE is limited to only one study in which mutation analyses of 10 patients were reported. ${ }^{1}$ The results of that study showed five novel mutations consisted of regulatory mutation, initiation codon change, splice mutation, nonsense mutation and 9bp-deletion mutation. Although C1-INH-HAE type I is usually inherited in an autosomal dominant manner, two Turkish families with autosomal recessive inheritance were reported in the literature. ${ }^{1,9}$ In our family cases, the inheritance was autosomal dominant. One of the twin children of the index patient had the mutation and the other did not.

The results of our study demonstrated that C1-INH-HAE type I may present with diverse clinical features in patients carrying the same mutation for C1-INH gene. Onset of clinical symptoms and signs of HAE started in a time period ranging between very early years of life to adulthood. Besides, symptoms varied in degree from very mild to severe as defined by different members of the family. When the proband was correctly diagnosed as C1-INH-HAE type I, the other family members were invited for examination and had the chance of correct diagnoses. Symptoms of HAE include mainly swelling on extremities, abdominal cramps, facial and laryngeal edema. ${ }^{1,10}$ Laryngeal edema without asphyxia was experienced by our patients whereas one older relative had died due to airway obstruction. As observed in our patients, abdominal attacks are very common in Turkish patients with HAE. ${ }^{1}$ In the present study, all patients were first misdiagnosed as having FMF and administered colchicine treatment for years. As expected, patients did not have any benefit from colchicine. Misdiagnosis as FMF was also reported in six of 70 patients in the study of Kesim et al. and a case report from Turkey. 1,11 Abdominal angioedema without skin swelling is a challenging problem in countries where FMF is an endemic disorder. Abdominal pain in HAE may also mimic acute abdominal disorders, which require urgent surgical procedures. High prothrombin fragment F1 and F2 and D-dimer levels are suggested to support HAE during acute angioedema attacks, which prevent patients from undergoing unnecessary abdominal surgery. ${ }^{12}$ Besides, elevated D-dimers in HAE attacks were not found to be associated with increased thrombotic risk. ${ }^{13}$ Overlooking patients with HAE gave rise to a very long lag time for diagnosis - up to 52 years as observed in one of our patients. Taking a detailed personal and familial medical history and suspicion for HAE is the key approach to make a correct diagnosis.

Treatment of C1-INH-HAE type I includes on demand or attack therapy and prophylaxis. The proband in our study was first observed when she was having a severe facial angioedema attack and put on fresh frozen plasma therapy immediately since C1INH concentrate was not available at the time. Then, she was followed-up by long-term prophylaxis with danazol. Danazol therapy was administered for three patients of the family and very well tolerated. We observed that a minimum dose of danazol could provide a very satisfying disease control. On the other hand, the patients were closely followed for potential adverse events on hormonal status and liver. Danazol may cause hormonal adverse events including virilization, decreased breast size, irregular vaginal bleeding or decreased libido, changes on lipid profiles leading to atherosclerosis, and hepatotoxicity. Cicardi et al. reported that menstrual irregularities were the main adverse events of danazol or danazol and stanozolol combination treatment. ${ }^{10}$ Zotter et al. observed that hirsutism was the most common adverse event, however, long-term danazol treatment with the lowest effective dose had resulted only a mild virilizing effect. ${ }^{14}$ Bork et al. reported that adverse events including hormonal disturbances, headache, weight gain, depression, and liver adenoma, resulted in discontinuation of therapy in 30 of 118 patients. They concluded that patients should be closely monitored due to the high risk of adverse events. ${ }^{15}$ Birjmohun et al. found no significant risk for atherosclerosis whereas Széplaki et al. recommended monitoring of lipid profiles to detect any development of early atherosclerosis. ${ }^{16,17}$ In a recent study, no hematological 
abnormalities, including erythrocytosis and/or polyglobulia, were detected during long-term danazol treatment. ${ }^{18}$ Our observations on patients receiving a very long period of danazol therapy did not revealed hormonal adverse events, as well as hematological or lipid profile abnormalities.

Hepatotoxicity is a well-known adverse event of danazol that may cause development of adenomas, focal nodular hyperplasia, and rarely hepatocellular carcinoma. ${ }^{19,20}$ Risk for hemangioma development increases in patients receiving danazol more than 10 years. Besides, danazol induced adenomas were also observed even after discontinuing the therapy.$^{19}$ Hepatocellular carcinoma is detected in very rare cases, especially in individuals treated for more than 10 years with high doses such as $>200 \mathrm{mg} / \mathrm{d} .{ }^{19}$ On the other hand, the lowest effective dose of danazol was not found to induce liver injury in HAE patients. ${ }^{21}$ According to the World Allergy Organization (WAO) guideline for the management of hereditary angioedema, liver ultrasound is recommended to be performed before danazol therapy, yearly during therapy, and 6 months after ceasing therapy. ${ }^{22}$ We observed development of liver hemangioma and hepatosteatosis with normal liver structure in two patients. They were all very satisfied with control of attacks. Patients were recommended to come to their routine follow-up visits since they were on a minimum dose of danazol and switching to tranexamic acid did not work well in one of them.

Androgens have anticoagulant and fibrinolytic effects; however, a possible thrombogenic effect of exogenous androgens is an important concern. Androgens may affect platelet aggregation, coagulation, and facilitate thrombosis. ${ }^{23}$ Although the link between thrombosis or premature cardiovascular disease and danazol is still unclear, danazol-induced thrombosis was reported in several cases. ${ }^{24-26}$ Danazol therapy was found to increase activation of coagulation in patients treated for more than two years. ${ }^{16}$ Depending on these reports, we did not initiate danazol prophylaxis in one patient having thrombotic cerebrovascular disease. Instead, she was put on weekly C1-INH concentrate infusions, which reduced the frequency of angioedema attacks. The efficacy of C1-INH concentrate is clearly demonstrated on both attack treatment and long-term prophylaxis in patients with HAE. ${ }^{27,28}$ Intravenous infusion of C1-INH concentrate, the only available and approved drug for HAE in Turkey, needs to be administered in health centers. Patient compliance is mandatory for the treatment. Self-administration of C1-INH concentrate at home needs training of patients and their relatives. ${ }^{22}$ Subcutaneous icatibant seems to be a relatively easier treatment for patients who live far away from health centers. On the other hand, for an easier administration, subcutaneous form of C1-INH concentrate is under investigation and phase II study results showed to be well tolerated and caused a dose-dependent increase in plasma levels. ${ }^{29}$

\section{CONCLUSION}

In the present study, we demonstrated a genetic mutation of C1-INH gene in a Turkish family with HAE and showed that longterm danazol prophylaxis might be effective for disease control. Patients with HAE may be overlooked in countries where FMF is endemic. Since phenotypic diversity may occur in the same family, clinicians should be aware of the signs and symptoms of HAE and consider it in the differential diagnosis to make an early diagnosis leading to prompt initiation of treatment. $\square$

\section{REFERENCES}

1. Kesim B, Uyguner ZO, Gelincik A, Mete Gökmen N, Sin AZ, Karakaya G, et al. The Turkish Hereditary Angioedema Pilot Study (TURHAPS): the first Turkish series of hereditary angioedema. Int Arch Allergy Immunol. 2011;156:443-50.

2. Cicardi M, Aberer W, Banerji A, Bas M, Bernstein JA, Bork K,et al. HAWK under the patronage of EAACI (European Academy of Allergy and Clinical Immunology). Classification, diagnosis, and approach to treatment for angioedema: consensus report from the Hereditary Angioedema International Working Group. Allergy. 2014;69:602-16.

3. Zuraw BL. The Pathophysiology of Hereditary Angioedema. World Allergy Organ J. 2010;3:S25-8

4. Gompels MM, Lock RJ, Abinun M, Bethune CA, Davies G, Grattan C, et al. C1 inhibitor deficiency: consensus document. Clin Exp Immunol. 2005;139:379-94.

5. Kalmár L, Hegedüs T, Farkas H, Nagy M, Tordai A. HAEdb: a novel interactive,locusspecific mutation database for the C1 inhibitor gene. Hum Mutat. 2005;25:1-5

6. Speletas M, Szilagyi A, Psarros F, Moldovan D, Magerl M, Kompoti M, et al. Hereditary angioedema: molecular and clinical differences among European populations. J Allergy Clin Immunol. 2015;135:570-3.

7. Bors A, Csuka D, Varga L, Farkas H, Tordai A, Füst G, et al. Less severe clinical manifestations in patients with hereditary angioedema with missense $\mathrm{C} 1 \mathrm{INH}$ gene mutations. J Allergy Clin Immunol. 2013;131:1708-11.
8. Pappalardo E, Caccia S, Suffritti C, Tordai A, Zingale LC, Cicardi M. Mutation screening of $C 1$ inhibitor gene in 108 unrelated families with hereditary angioedema: functional and structural correlates. Mol Immunol. 2008;45:3536-44.

9. Büyüköztürk S, Eroğlu BK, Gelincik A, Uzümcü A, Ozşeker F, Colakoğlu B, et al. A Turkish family with a novel mutation in the promoter region of the $\mathrm{C} 1$ inhibitor gene. J Allergy Clin Immunol. 2009;123:962-4.

10. Cicardi M, Castelli R, Zingale LC, Agostoni A. Side effects of long-term prophylaxis with attenuated androgens in hereditary angioedema: comparison of treated and untreated patients. J Allergy Clin Immunol. 1997;99:194-6.

11. Sarici G, Koca R, Tekin NS, Altinyazar HC. A family with hereditary angioedema having been followed as familial Mediterranean fever. Turkderm 2009;43:29-31.

12. Cugno M, Zanichelli A, Bellatorre AG, Griffini S, Cicardi M. Plasma biomarkers of acute attacks in patients with angioedema due to C1-inhibitor deficiency. Allergy. 2009:64:254-7.

13. Reshef A, Zanichelli A, Longhurst H, Relan A, Hack CE. Elevated D-dimers in attacks of hereditary angioedema are not associated with increased thrombotic risk. Allergy. 2015;70:506-13.

14. Zotter Z, Veszeli N, Csuka D, Varga L, Farkas H. Frequency of the virilising effects of attenuated androgens reported by women with hereditary angioedema. Orphanet $J$ Rare Dis. 2014;9:205. 
15. Bork K, Bygum A, Hardt J. Benefits and risks of danazol in hereditary angioedema: a long-term survey of 118 patients. Ann Allergy Asthma Immunol. 2008;100:153-61.

16. Birjmohun RS, Kees Hovingh G, Stroes ES, Hofstra JJ, Dallinga-Thie GM, Meijers $\mathrm{JC}$, et al. Effects of short-term and long-term danazol treatment on lipoproteins coagulation, and progression of atherosclerosis: two clinical trials in healthy volunteers and patients with hereditary angioedema. Clin Ther. 2008;30:2314-23.

17. Széplaki G, Varga L, Valentin S, Kleiber M, Karádi I, Romics L, et al. Adverse effects of danazol prophylaxis on the lipid profiles of patients with hereditary angioedema J Allergy Clin Immunol. 2005;115:864-9.

18. Köhalmi KV, Veszeli N, Zotter Z, Csuka D, Benedek S, Imreh É, et al. The effect of long-term danazol treatment on haematological parameters in hereditary angioedema. Orphanet J Rare Dis. 2016;11:18.

19. Bork K, Schneiders V. Danazol-induced hepatocellular adenoma in patients with hereditary angio-oedema. J Hepatol. 2002;36:707-9.

20. Helsing P, Nielsen EW. Hepatocellular focal nodular hyperplasia after danazol treatment for hereditary angio-oedema. Acta Derm Venereol. 2006;86:272-3.

21. Farkas H, Czaller I, Csuka D, Vas A, Valentin S, Varga L, et al. The effect of longterm danazol prophylaxis on liver function in hereditary angioedema-a longitudinal study. Eur J Clin Pharmacol. 2010;66:419-26.

22. Craig $\mathrm{T}$, Aygören-Pürsün $\mathrm{E}$, Bork $\mathrm{K}$, Bowen $\mathrm{T}$, Boysen $\mathrm{H}$, Farkas $\mathrm{H}$, et al. WAO Guideline for the Management of Hereditary Angioedema. World Allergy Organ J. 2012;5:182-99.

23. Ferenchick GS. Anabolic/androgenic steroid abuse and thrombosis: is there a connection? Med Hypotheses. 1991;35:27-31.

24. Sahraian MA, Mottamedi M, Azimi AR, Moghimi B. Androgen-induced cerebral venous sinus thrombosis in a young body builder: case report. BMC Neurol. 2004:4:22.

25. Kumar GS, Roopesh Kumar VR, Gopalakrishnan MS, Shankar Ganesh CV, Venkatesh MS. Danazol-induced life-threatening cerebral venous thrombosis in a patient with aplastic anemia. Neurol India. 2011;59:762-4

26. Alvarado RG, Liu JY, Zwolak RM. Danazol and limb-threatening arterial thrombosis: two case reports. J Vasc Surg. 2001;34:1123-6.

27. Bork K, Craig TJ, Bernstein JA, Feuersenger H, Machnig T, Staubach P. Efficacy of C1 esterase inhibitor concentrate in treatment of cutaneous attacks of hereditary angioedema. Allergy Asthma Proc. 2015;36:218-24.

28. Pedrosa M, Lobera T, Panizo C, Jurado J, Caballero T. Long-term prophylaxis with C1-inhibitor concentrate in patients with hereditary angioedema. J Investig Allergol Clin Immunol. 2014;24:271-3.

29. Zuraw BL, Cicardi M, Longhurst HJ, Bernstein JA, Li HH, Magerl M, et al. Phase II study results of a replacement therapy for hereditary angioedema with subcutaneous C1-inhibitor concentrate. Allergy. 2015;70:1319-28.
MAILING ADDRESS:

Gulsen Akoglu

Dermatovenereology Clinic,

Ataturk Training and Research Hospital,

Bilkent

Ankara, Turkey.

Email:gusemd@yahoo.com

How to cite this article: Akoglu G, Kesim B, Yildiz G, Metin A. Outcomes of long term treatments of type I hereditary angioedema in a Turkish family. An Bras Dermatol. 2017;92(5):655-60. 